\title{
Combined management of perianal rhabdomyosarcoma with chemotherapy, radical surgery, and irradiation: A series of three consecutive children
}

\author{
Antti I Koivusalo*, Risto J Rintala, Mikko P Pakarinen \\ Children's Hospital, Section of Pediatric Surgery, University of Helsinki, Finland
}

\section{A R T I C L E I N F O}

\section{Article history:}

Received 20 October 2018

Accepted 30 October 2018

Available online $\mathrm{xxxx}$

\section{Key words:}

Rhabdomyosarcoma

Perianal

Abdominoperineal excision

\begin{abstract}
A B S T R A C T
Background and aim: We describe a series of three successive patients with perianal rhabdomyosarcoma (PRMS) from 2014 to 2017 managed with combined chemotherapy, radical surgery, and radiotherapy.

Methods: Ethical consent was obtained. Data including tumor presentation, treatment, and survival was collected from hospital reports.

Results: Two girls aged 15 and 16 years (patient \#1 and \#2) and one boy aged five years (patient \#3) were referred because of a suspected perianal abscess. MRI showed large perianal tumors from 7 to $12 \mathrm{~cm}$ in diameter that surrounded or infiltrated the anal sphincters and were inconsistent with abscess. Tumor biopsies showed RMS of alveolar (\#1 and \#2) and embryonal (\#3) types. Patient \#1 had lymph node and bone metastases, patient \#2 lymph node metastases, and patient \#3 no metastases. Pretreatment staging, IRS Clinical Group, and Risk Groups were: Stage 4, II, high; Stage 3, GII, intermediate; and Stage 3, I, low, respectively. All underwent colostomy before neoadjuvant chemotherapy (CWS-RMS 2009 program). Neoadjuvant chemotherapy failed to clear the tumors from anal sphincters preventing anus-saving surgery, and all patients underwent abdominoperineal excision. All removed specimens had free margins with negative lymph nodes. After adjuvant chemotherapy and local radiation, the patients were tumor free after 48, 13, and 18 months.

Conclusion: In PRMS local surgical control required abdominoperineal excision. Confusion between PRMS and abscess may cause unnecessary delay in management.

Level of Evidence: IV (Treatment Study, Case Series with no Comparison Group).
\end{abstract}

(c) 2018 Elsevier Inc. All rights reserved.
Rhabdomyosarcoma (RMS) accounts for two-thirds of childhood soft tissue sarcomas and $7-8 \%$ of all pediatric solid malignant tumors [1]. Perineal or perianal location of RMS is rare and occurs in $<2 \%$ of the cases [2]. Outcome of patients with perianal or perineal RMS has been regarded poor with combined survival only from 20-50\% [3-5]. Treatment options have included chemotherapy, conservative or radical excision of the tumor and local radiotherapy. In selected patients a combination of brachytherapy in the treatment protocol may improve the chances for non-mutilating surgery [6-9].

In this study we present a series of three successive patients with a large perianal RMS (PRMS) that affected the levator ani and the anal sphincter muscles. We describe the stage and histology of the tumors, diagnostics, treatment, complications and survival.

\footnotetext{
* Corresponding author at: Children's Hospital, Section of Pediatric Surgery, Stenbackinkatu 11, PL 281, 00270, Helsinki, Finland. Tel.: + 358 504272412; fax: + 358 94714705.

E-mail address: antti.koivusalo@hus.fi (A.I. Koivusalo).
}

\section{Materials and methods}

Consent from the local ethical board was obtained. PRMS was diagnosed in three successive patients in $2013(\mathrm{n}=1)$ and $2016(\mathrm{n}=2)$. Patients \#1 and \#2 were teenage girls aged 15 and 16 years and patient \#3 was a boy aged five years. All were previously healthy. Data was collected from hospital records. All patients were initially referred by a general practitioner with suspected perianal abscess.

\section{Results}

Initial MRI imaging showed main tumor mass from 7 to $12 \mathrm{~cm}$ of diameter In all three patients. This was over the left buttock, in a horse-shoe fashion round the anal canal and tumor infiltration between levator ani and internal anal sphincter muscles. MRI showed enlarged suspected metastatic lymph nodes in left inguinal and right para-iliac locations and (\#1) and in mesocolic fat and in left iliac bone (\#2).

Due to initial misdiagnosis of perianal abscess the biopsies occurred from 11 to 31 days after the initial referral. Patient \#3 underwent a negative explorative incision. Histologic diagnosis was obtained by an 
Table 1

Clinical data and initial staging.

\begin{tabular}{|c|c|c|c|c|c|c|c|c|}
\hline Patient & Age & Gender & Histology & Mutation & $\mathrm{N}$ & M & $\begin{array}{l}\text { Risk } \\
\text { group }\end{array}$ & Stage \\
\hline 1 & 15 & Female & $\begin{array}{l}\text { Alveolar / } \\
\text { unfavorable }\end{array}$ & $\begin{array}{l}\text { FOX } 01 \\
\mathrm{t}(2 ; 13)(\mathrm{q} 35 ; \mathrm{q} 14)\end{array}$ & N1 & M0 & High & III \\
\hline 2 & 16 & Female & $\begin{array}{l}\text { Alveolar / } \\
\text { unfavorable }\end{array}$ & $\begin{array}{l}\text { FOX } 01 \\
\mathrm{t}(2 ; 13)(\mathrm{q} 35 ; \mathrm{q} 14)\end{array}$ & N1 & M1 & High & IV \\
\hline 3 & 5 & Male & $\begin{array}{l}\text { Embryonal / } \\
\text { favorable }\end{array}$ & $\mathrm{N} / \mathrm{A}$ & NO & M0 & Low & I \\
\hline
\end{tabular}

open tumor biopsy in \#2 and \#3 and from inguinal lymph node metastasis in \#1. Histopathology, staging and prognostic risk group class are outlined in Table 1.

Due to the evident tumor infiltration into anal sphincter muscles upfront surgery was not considered feasible in any of the three patients. All patients underwent sigmoid colostomy before chemotherapy was initiated because of pain, inflammation and ulceration and difficulties in defecation caused by the tumors.

At the end of neoadjuvant chemotherapy MRI imaging indicated moderate response in patient \#1, whereas in \#2 and \#3 the radiologic response was poor (Figs. 1 and 2). In all three patients infiltration of the tumor into anal sphincters and levator ani muscles was unchanged. Anus saving surgery was considered in all patients. Brachytherapy was considered but abandoned because all three still had a substantial infiltrating residual tumor and because experience from brachytherapy in PRMS in children was sparse [6,7]. The decision for abdominoperineal excision and permanent colostomy was eventually made in agreement with all three patients and their caregivers as it was felt that anus saving surgery would carry also a high risk of tumor recurrence and anal incontinence.

Operations included excision of the residual tumor with anus, and total mesocolic excision of the rectosigmoid distal to the colostomy, and pathological lymph nodes. In patients \#1 and \#2 the excision included a narrow strip of the posterior vaginal wall.

Histopathology findings in the surgical specimens were as follows: \#1 - within the tumor mass an area of $2.5 \mathrm{~cm}$ in diameter with vital RMS, free tumor margins, negative mesenteric and iliac lymph nodes;

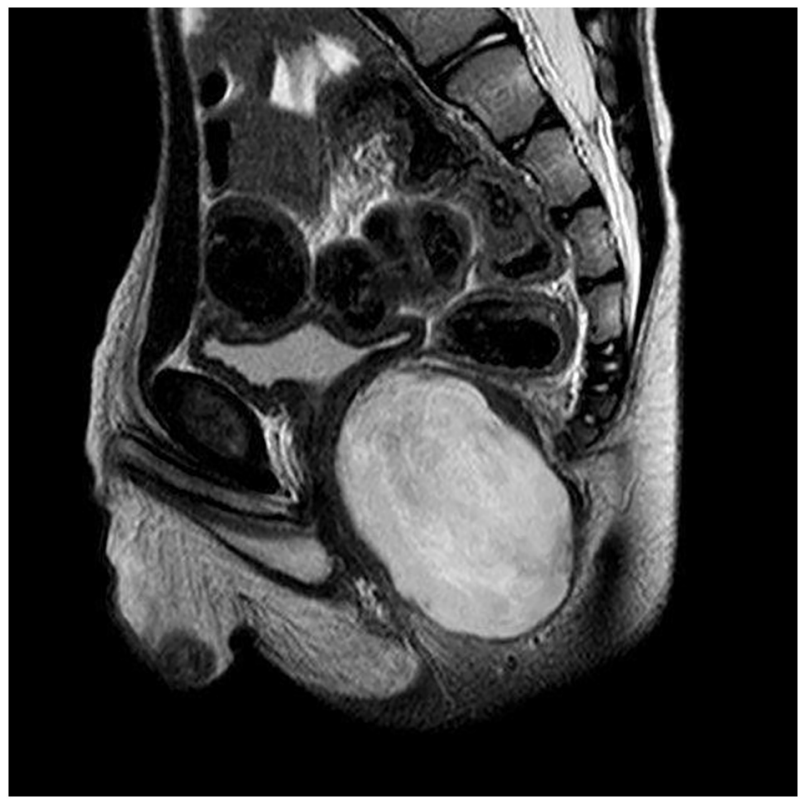

Fig. 1. Perianal rhabdomyosarcoma in patient \#3. The tumor was RMS of embryonal type and infiltrated the levator ani muscles and external anal sphincters.

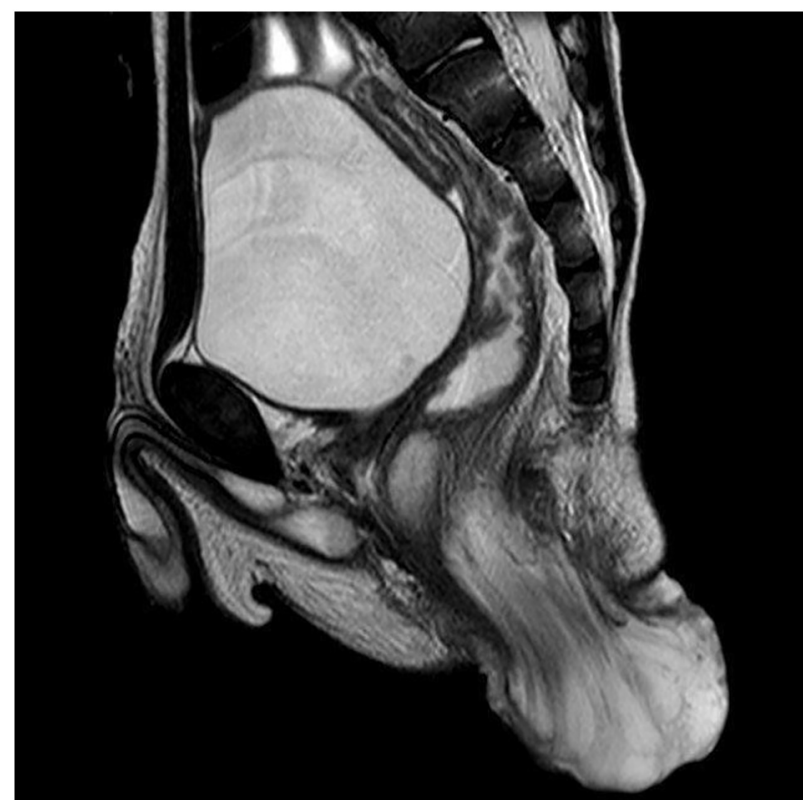

Fig. 2. Response to neoadjuvant chemotherapy in patient \#3, preoperative MRI imaging Overall response is poor, the tumor has not diminished in size, partially prolapsed from the perianal location and still attached to the levator ani muscles and external anal sphincters.

\#2 - islets of vital RMS within the removed tumor mass, free tumor margins, negative mesenteric and iliac lymph nodes; \#3 - a substantial amount of vital RMS within the removed tumor mass, free tumor margins, negative mesenteric and iliac lymph nodes. In \#3, the tumor response to neoadjuvant chemotherapy was poor and this was thereafter administered according to a high risk protocol (See Table 2).

\subsection{Postoperative course and complications}

Patients \#1 and \#3 had primary wound healing. Patient \#2 had dehiscence of the perineal incision which eventually healed after a gracilis muscle flap was performed. This resulted in a 4-week delay in postoperative chemotherapy and irradiation. Patients \#2 and \#3 needed to undergo a laparotomy for small bowel obstruction. During the adjuvant chemotherapy patient \#1 suffered an episode of pulmonary thromboembolism and both patients \#1 and \#3 developed vincristine-induced neuropathy. All patients were referred to pediatric neuropsychological surveillance and both girls were referred for gynecological surveillance.

Table 2

Chemotherapy and irradiation.

\begin{tabular}{|c|c|c|c|c|}
\hline Patient & Age & $\begin{array}{l}\text { Neoadjuvant } \\
\text { chemo }\end{array}$ & $\begin{array}{l}\text { Postoperative } \\
\text { maintenance } \\
\text { \& irradiation }\end{array}$ & Adjuvant chemo \\
\hline 1 & 15 & $\begin{array}{l}4 \text { courses: } \\
\text { Carboplatin } \\
\text { Epirubisin } \\
\text { Vincristin }\end{array}$ & $\begin{array}{l}\text { Local irradiation }+ \\
\text { Oral } \\
\text { Trofosfamid } \\
\text { Etoposid }\end{array}$ & $\begin{array}{l}\frac{4 \text { courses }}{\text { Ifosfamide }} \\
\text { Vincristin, } \\
\text { Etoposide }\end{array}$ \\
\hline 2 & 16 & $\begin{array}{l}4 \text { courses: } \\
\text { Carboplatin } \\
\text { Epirubisin } \\
\text { Vincristin }\end{array}$ & $\begin{array}{l}\text { Local irradiation }+ \\
\text { Oral } \\
\text { Trofosfamid } \\
\text { Etoposid }\end{array}$ & $\begin{array}{l}\frac{4 \text { courses }}{\text { Ifosfamide }} \\
\text { Vincristin, } \\
\text { Etoposide }\end{array}$ \\
\hline 3 & 5 & $\begin{array}{l}3 \text { courses: } \\
\text { Ifosfamide } \\
\text { Vincristin } \\
\text { Actinomycin -d }\end{array}$ & Local irradiation & $\begin{array}{l}6 \text { courses } \\
\text { Topotecan carboplatin (2) } \\
\text { carboplatin etoposide (2) } \\
\text { Cyclofosfamide vincristin } \\
\text { Doxorubicin }(2)\end{array}$ \\
\hline
\end{tabular}




\subsection{Follow-up}

After 48, 14 and 19 months respectively of follow-up all patients have no evidence of tumor recurrence. Patient 1 and 3 have returned to school and resumed their former activities with mild psychological problems. Patient 2 has psychological problems because of disfigured perineal region and colostomy which currently impedes her return to school.

\section{Discussion}

The present study described three patients with perianal rhabdomyosarcoma (PRMS) were treated by combined chemotherapy and ablative surgery. As reported by Hill et al. in 2002, PRMS can be confused with perianal abscess which can cause delay before the correct diagnosis is made [10]. In our patients the choice of the treatment included a standard regimen of chemotherapy, surgery and irradiation. The choice of surgery in all patients was abdominoperineal excision which provided tumor free margins and harvest of mesenteric lymph nodes. All patients remain tumor-free but the follow-up is too short to provide 5-year survival. Treatment of RMS aims primarily for survival but at the same time mutilating surgery should preferably be avoided. Abdominoperineal excision may be regarded as a maximally invasive or near mutilating procedure and search for any anus-preserving options can be considered justified. Local control of the disease is, however, crucial for the successful management [11,12].

Fuchs et al. in 2014 reported 64\% five-year survival in patients with perineal $(n=8)$ or perianal $(n=24)$ rhabdomyosarcoma treated with chemotherapy and conventional radiotherapy with or without mutilating surgery from 1986 to 2008 . They concluded that tumor size $<5 \mathrm{~cm}$ diameter, age $<10$ years, low IRS group, negative locoregional lymph nodes and embryonal histology were prognostically favorable factors. A post-operative questionnaire for fecal continence identified incontinence in $40 \%$ of responders [5].

A combination of conservative surgery and brachytherapy may provide better chances of organ saving surgery without compromising survival or recurrence [7]. Successful management of anal and distal rectal cancer with brachytherapy with or without conservative surgery has already been reported [13]. In RMS of bladder /prostate and vulva/vagina considerable results have been achieved of conservative surgery combined with brachytherapy $[14,15]$.

Conservative surgery with brachytherapy or with proton beam radiation has also been used in perineal and PRMS but due to the rarity of the disease the number of reported cases is low. Fuchs et al. (2016) [6] reported two patients and Demoor-Goldschmidt et al. (2015) [7] one patient with PRMS treated with combined surgery and brachytherapy. The experience with the proton beam therapy is also limited to a few patients [16,17]. A limitation of brachytherapy is its availability and the risk of adverse effects on the intestine [9] and anal continence. After conservative treatment of perineal or perianal RMS fecal incontinence may be a significant a problem. Fecal incontinence may, however, be effectively treated by various methods including ACE-appendicostomy [18].

Our decision to perform abdominoperineal excision was based on the poor prognostic signs including of tumor site, tumor size, histology, and, we wanted to ensure good local control. Not enough was known of the efficiency of brachytherapy in PRMS encompassing the anus and the sphincters. In a center with access to and experience of brachytherapy and intraoperative proton beam radiation the choice of treatment could, of course, have been different. Abdominoperineal excision causes a significant disfigurement and combined with radiotherapy considerable problems with skin irritation and pressure wounds being the kind of morbidity that for a teenager is hard to accept. Abdominoperineal excision may also detrimental to sexual function in male and female alike $[19,20]$. When considered as the only surgical means to provide local control of RMS as well as survival abdominoperineal excision can be an acceptable choice which still offers a moderately good quality of life to adult patients [20].

\section{CRediT authorship contribution statement}

Antti I. Koivusalo: Conceptualization, Investigation, Formal analysis, Writing - original draft, Writing - review \& editing. Risto J. Rintala: Investigation, Formal analysis, Writing - review \& editing. Mikko P. Pakarinen: Investigation, Formal analysis, Writing - review \& editing.

\section{References}

[1] McDowell HP. Update on childhood rhabdomyosarcoma. Arch Dis Child 2003;88: 354-7.

[2] Raney Jr RB, Donaldson MH, Sutow WW, et al. Special considerations related to primary site in rhabdomyosarcoma: experience of the intergroup rhabdomyosarcoma study, 1972-76. Natl Cancer Inst Monogr 1981;56:69-74.

[3] Okamura K, Yamamoto H, Ishimaru Y, et al. Clinical characteristics and surgical treatment of perianal and perineal rhabdomyosarcoma: analysis of Japanese patients and comparison with IRSG reports. Pediatr Surg Int 2006;22:129-34

[4] Casey DL, Wexler LH, LaQuaglia MP, et al. Patterns of failure for rhabdomyosarcoma of the perineal and perianal region. Int J Radiat Oncol Biol Phys 2014;89(1):82-7.

[5] Fuchs J, Dantonello TM, Blumenstock G, et al. Treatment and outcome of patients suffering from perineal/perianal rhabdomyosarcoma: results from the CWS trials retrospective clinical study. Ann Surg 2014;259:1166-72.

[6] Fuchs J, Paulsen F, Bleif M, et al. Conservative surgery with combined high dose rate brachytherapy for patients suffering from genitourinary and perianal rhabdomyosarcoma. Radiother Oncol 2016;121:262-7.

[7] Demoor-Goldschmidt C, Dumoucel S, Haie-Meder C, et al. Conservative management of a perianal rhabdomyosarcoma in a 2-year old child by Papillon's technique. Radiat Oncol 2015;10:108.

[8] Laskar S, Pilar A, Khanna N, et al. Interstitial brachytherapy for pediatric soft tissue sarcoma: evolving practice over three decades and long-term outcomes. Pediatr Blood Cancer 2018;65:e27112.

[9] Folkert MR, Tong WY, LaQuaglia MP, et al. 20-year experience with intraoperative high-dose-rate brachytherapy for pediatric sarcoma: outcomes, toxicity, and practice recommendations. Int J Radiat Oncol Biol Phys 2014;90:362-8.

[10] Hill DA, Dehner LP, Gow KW, et al. Perianal rhabdomyosarcoma presenting as a perirectal abscess: a report of 11 cases. J Pediatr Surg 2002;37:576-81.

[11] Réguerre Y, Martelli H, Rey A, et al. Local therapy is critical in localised pelvic rhabdomyosarcoma: experience of the International Society of Pediatric Oncology Malignant Mesenchymal Tumor (SIOP-MMT) committee. Eur J Cancer 2012;48: 2020-7.

[12] Dantonello TM, Int-Veen C, Schuck A, et al. Cooperative Weichteilsarkom Studiengruppe. Survival following disease recurrence of primary localized alveolar rhabdomyosarcoma. Pediatr Blood Cancer 2013;60:1267-73.

[13] Frin AC, Evesque L, Gal J, et al. Organ or sphincter preservation for rectal cancer. The role of contact X-ray brachytherapy in a monocentric series of 112 patients. Eur J Cancer 2017;72:124-36.

[14] Chargari C, Haie-Meder C, Guérin F, et al. Brachytherapy combined with surgery for conservative treatment of children with bladder neck and/or prostate rhabdomyosarcoma. Int J Radiat Oncol Biol Phys 2017;98:352-9.

[15] Martelli H, Borrego P, Guérin F, et al. Quality of life and functional outcome of male patients with bladder-prostate rhabdomyosarcoma treated with conservative surgery and brachytherapy during childhood. Brachytherapy 2016;15:306-11.

[16] Mizumoto M, Murayama S, Akimoto T, et al. Preliminary results of proton radiotherapy for pediatric rhabdomyosarcoma: a multi-institutional study in Japan. Cancer Med 2018;7:1870-4

[17] Takizawa D, Oshiro Y, Mizumoto M, et al. Proton beam therapy for a patient with large rhabdomyosarcoma of the body trunk. Ital J Pediatr 2015;41:90.

[18] Chan DS, Delicata RJ. Meta-analysis of antegrade continence enema in adults with faecal incontinence and constipation. Br J Surg 2016;103:322-7.

[19] Kasparek MS, Hassan I, Cima RR, et al. Long-term quality of life and sexual and urinary function after abdominoperineal resection for distal rectal cancer. Dis Colon Rectum 2012;55:147-54.

[20] González E, Holm K, Wennström B, et al. Self-reported wellbeing and body image after abdominoperineal excision for rectal cancer. Int J Colorectal Dis 2016:31:1711-7. 